\title{
Cancer mortality in the British rubber industry: 1946-80
}

\author{
T SORAHAN, ${ }^{1}$ H G PARKES, ${ }^{2}$ C A VEYS, ${ }^{2}$ AND J A H WATERHOUSE ${ }^{1}$
}

From the Cancer Epidemiology Research Unit, ${ }^{1}$ University of Birmingham, Edgbaston, Birmingham B15 2TH, and British Rubber Manufacturers' Association, ${ }^{2}$ Health Research Unit, Birmingham B1 IEQ, UK

ABSTRACT The mortality experienced by a cohort of 36445 rubber workers during $1946-80$ has been investigated. These workers were all male operatives first employed in any one of the 13 participating factories in 1946-60; all had worked continuously in the industry for a minimum period of one year. Compared with the general population, statistically significant excesses relating to cancer mortality were found for cancer of the stomach $(E=245 \cdot 9, O=282, S M R=115)$, primary cancer of the liver $(E=12 \cdot 8, O=22, S M R=172)$, cancer of the lung $(E=892 \cdot 7, O=1191$, SMR $=133)$, and all neoplasms $(E=2165 \cdot 2, O=2487, S M R=115)$. Statistically significant deficits were found for cancer of the prostate $(E=79 \cdot 7, O=59, S M R=74)$ and cancer of the testis $(\mathrm{E}=10 \cdot 3, \mathrm{O}=4, \mathrm{SMR}=39)$. The method of regression models in life tables (RMLT) was used to compare the duration of employment in the industry, the duration in "dust exposed" jobs, and the duration in "fume and/or solvent exposed" jobs of those dying from causes of interest with those of all matching survivors. Significant positive associations were found only for cancer of the stomach and cancer of the lung. The results of the RMLT analysis are independent of those from the SMR analysis, and the study has provided further evidence of a causal association between the risks of lung and stomach cancer and certain occupational exposures in the rubber industry.

In 1982 the Health Research Unit of the British Rubber Manufacturers' Association and the Cancer Epidemiology Research Unit of the University of Birmingham published a report describing the mortality experience of a large cohort of rubber workers in the United Kingdom. ${ }^{1}$ The study found an "overall excess cancer mortality in the British rubber industry that is accounted for almost entirely by the observed excess of lung and stomach cancer." Apart from a small excess of oesophageal cancer, there was no evidence of any significant excess cancer mortality for other sites of cancer. The absence of any excess of bladder cancer affecting men who entered the industry after 1950 was noted.

An IARC working group also published an evaluation of carcinogenic risks in the rubber industry in the same year. ${ }^{2}$ For lung cancer and stomach cancer, this report concluded that there was sufficient evidence for an excess occurrence in rubber workers and limited evidence for a causal association with occupational exposures.
This present study consolidates the data from earlier work, incorporates a further five year period of follow up, and reports more detailed analyses of relations between the risks of cancer mortality and job histories.

\section{Study population}

The study population (comprising three five year entry cohorts) has been described elsewhere ${ }^{1}$ but may

Table 1 Description of occupations

\begin{tabular}{cl}
\hline Job No & Description \\
\hline 1 & $\begin{array}{l}\text { Crude material storeman } \\
\text { Compounding, weighing, mixing, reforming, } \\
\text { washing, etc } \\
\text { Latex mixing, frothing, dipping } \\
\text { Extruding, calendering, spreading, etc } \\
\text { Component building, preparation, } \\
\text { assembling, etc } \\
\text { Vulcanising, curing, moulding press, } \\
\text { autoclave, pan } \\
\text { Inspection, painting, trimming, etc } \\
\text { Finished goods, stores, packaging, despatch } \\
\text { Site workers, internal transport, general } \\
\text { truck drivers, etc } \\
\text { Engineering and building maintenance }\end{array}$ \\
\hline
\end{tabular}


Sorahan, Parkes, Veys, and Waterhouse $\frac{\frac{0}{c}}{\bar{c}}$

be summarised as all male operatives first employed in any one of the 13 participating factories during 1946-60 inclusive, and who worked continuously in the industry for a minimum period of one year. Detailed job histories-defined in terms of 10 occupations or departments (table 1)-were recorded for each employee.

Follow up procedures have also been described elsewhere. ${ }^{1}$ Before the present analysis was carried out, however, the vital status of each individual-as recorded in the computer file-was double checked with source data. Such data were held either by the National Health Service Central Register (NHSCR) at Southport, the General Register Office at Edinburgh, or the Health and Safety Executive. (The latter provided follow up information on men who featured in their own study of rubber workers. ${ }^{3}$ ) Company pension schemes are no longer generally being used for follow up, and workers formerly traced through such schemes are now "flagged" with the NHSCR at Southport.

Table 2 shows the vital status of the study population on the closing date of the survey. Only $3.7 \%$ were untraced. For those known to have died a death certificate was obtained with the underlying cause of death coded to the 8th revision of the ICD.

Table 2 Vital status at closing date of study, 31 December 1980

\begin{tabular}{lcr}
\hline & No & \multicolumn{1}{c}{$\%$} \\
\hline Traced alive & 24938 & $68 \cdot 4$ \\
Emigrated & 1228 & $3 \cdot 4$ \\
No trace & 1340 & $3 \cdot 7$ \\
Deceased & $8939^{*}$ & $24 \cdot 5$ \\
Total & $36445 \dagger$ & $100 \cdot 0$ \\
\hline
\end{tabular}

*Includes 75 deaths for which cause is unknown.

†Note 246 canteen workers listed in 1975 as "production workers" together with four duplicates have now been removed from the study.

\section{Methods}

The mortality experience of this cohort was compared with that which might have been expected to occur if rates of mortality for the general population of England and Wales or of Scotland had been operating on the study cohort, having due regard to the composition of the study cohort by age, sex, and calendar year.

Expectations based on person years at risk (pyr) were calculated using the Manyears computer program developed by $\mathbf{J}$ Peto. Individuals entered the pyr at the end of the first year of their employment and left on the date of death, date of embarkation, or the closing date of the study (31 December 1980), whichever was the earlier. Former employees who were untraced left the pyr on the date last known alive. $\frac{2}{3}$
Individuals were "censored" on reaching their 85 th $\bar{\alpha}$ birthday-thus no contributions were made to expected or observed numbers past this age. This was $\overrightarrow{\vec{F}}$ done for two reasons: firstly, national mortality rates $-\overrightarrow{-}$ are available only for the open ended age group $\geqslant 85$, 등 and the composition of this age group in the general population by individual years of age may differ from $\vec{\nabla}$ that of the study population and, secondly, any indi- $\frac{\alpha}{\sim}$ viduals incorrectly traced as "flagged alive" (because ${ }^{\infty}$ their death was not recorded in the main index files at $\overrightarrow{0}$ Southport or Edinburgh) would make a particularly $\vec{\overrightarrow{ }}$ large contribution to expectations for this age group.

This placed the mortality experience of the study cohort in broad perspective. The differences found $\frac{\Phi}{3}$ between the observed mortality of an industrial cohort and an expected experience based on rates of ${ }_{\sigma}^{\omega}$ mortality for the general population, however, clearly $\omega$ depend on factors other than specific occupational exposures. ${ }^{4}$ Such factors will include selection effects음 within the workforce as well as the regional and socialcomposition of the study cohort. The method of $c$ regression models in life tables (RMLT) was used, $\underset{\mathrm{D}}{\vec{D}}$ therefore, to test the null hypothesis of no effect on $\rightarrow$ mortality from occupational exposure in the rubber $\odot$ industry. ${ }^{5-7}$ Such exposures were here estimated crudely in terms of duration of employment in different occupations.

This method was used to compare the estimated occupational exposures of those who died in a given $\frac{2}{8}$ year of follow up with those of all matching survivors $\stackrel{\otimes}{\varrho}$ in the same year of follow up while controlling for $\overrightarrow{\vec{B}}$

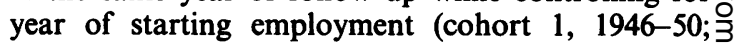
cohort 2, 1951-5; cohort 3, 1956-60), age at starting employment (15-, 20-, 25-, 30-, 45-, श 55); industry? sector (tyre, general rubber goods); and country of residence (England/Scotland). Follow up is measured $\frac{\mathbb{}}{3}$ from date of starting employment.

The data were first divided into a large number of subgroups by levels of the controlling variables mentioned above. For each subgroup (or subcohort) a life table was constructed, giving for each year of follow up the number entering that year of follow up, the number dying from the cause under investigation, $\frac{D}{2}$ and the mean cumulative exposure of these two categories. $^{67}$

The extent of occupational exposure was estimated $N$ in three ways:

(1) cumulative duration of employment in the ${ }^{\omega}$ industry (irrespective of which departments were worked in);

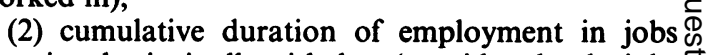
associated principally with dust (considered to be jobs 1, 2, and 4); and

(3) cumulative duration of employment in jobs $\frac{\text { }}{\mathbb{D}}$ associated principally with fume or solvents or both $\frac{\mathrm{O}}{\mathrm{O}}$ 
(considered to be jobs 4, 5, 6, and 7).

Of those who leave employment in any given year of follow up, a proportion will do so on the grounds of ill health. This group will, therefore, tend to be less healthy and, consequently, will have a higher rate of mortality than those remaining in employment. This effect is known as the "survivor population effect" and refers to a continuing selection process whereby the fittest remain or survive in the industry. ${ }^{8}$ For exposure estimates 2 and 3 it was possible to include "duration of employment in the rubber industry" as a controlling factor, to try and control for any survivor population effect in the data. Three levels of duration of employment in the rubber industry were considered $(1-2,3-7, \geqslant 8$ completed integer years). (A worker who was employed for 5 years 3 months would be placed in a "1-2" group for the first three years of follow up, and would be moved into a "3-7" group for all later years of follow up.)

The null hypothesis of no effect on mortality from the exposure is that the deaths in each year of follow up are a random sample from the entrants to that year and that the difference in the mean cumulative exposures of these two categories should be zero.

A test statistic was calculated to determine the probability of observing by chance alone the difference found between the exposures of those who have died and the exposures of the matching survivors - that is, if the null hypothesis is true. Since it is asymptotically normally distributed, a test statistic greater than 1.96 results in the rejection of the null hypothesis at the $5 \%$ level.

Several complementary analyses were also carried out in which two groups of workers were directly compared with each other with respect to mortalityfor example, lung cancer mortality among tyre sector workers compared with general rubber goods workers, or stomach cancer mortality among those employed in jobs 1,2 , or 4 for at least 12 months compared with those never so employed. These analyses make use of the RMLT computer programmes, and the approach is equivalent to the log-rank method used in the analysis of clinical trials.

The method was also used to estimate parameters of simple dose effect models-for example, latent period, doubling dose (exposure required to double the risk), and linearity of dose response. Latent period is not defined here as the interval between first exposure and death. Instead, exposure received in each year of employment is assumed to have a maximum effect $L$ years later, where $L$ is the optimum latent period. The procedures described above were repeated except that the cumulative exposure for each individual in each year of follow up was transformed into a relative risk predicted by the model under consideration. The risk of mortality predicted by the model for those who had died was compared with the risks of mortality predicted by the model for all matching survivors. A log likelihood was calculated to measure the goodness of fit of the specific dose effect model under consideration. The values of the parameters resulting in the highest likelihood were taken to be the "best" estimates of these parameters-maximum likelihood estimates (mle) (see appendix $\mathbf{A}$ ).

\section{Results}

\section{SMR APPROACH}

The existence of any "healthy worker effect" in the data is best investigated by calculating SMRs for all causes for successive five year periods from first employment (irrespective of how long any individual remains in the industry). ${ }^{8}$ These are shown in table 3. There is a general trend of increasing SMRs over the follow up period, although the SMR for the last period is not consistent with this trend. Results are also given in table 3 for all cancers and for all noncancers. There is little evidence of a healthy worker effect affecting cancer mortality.

Table 4 shows the overall results for cancer mortality by site. Compared with the general population, there are statistically significant excesses for cancer of the stomach, primary cancer of the liver, cancer of

Table 3 Mortality from all causes, all cancers, and all non-cancers by successive periods from first employment (irrespective of how long any individual remains in the industry): 1946-80

\begin{tabular}{|c|c|c|c|c|c|c|c|c|c|}
\hline \multirow{2}{*}{$\begin{array}{l}\text { Years since } \\
\text { first employed }\end{array}$} & \multicolumn{3}{|c|}{ All causes } & \multicolumn{3}{|c|}{ All cancers (ICD 8: 140-239) } & \multicolumn{3}{|c|}{ All non-cancers } \\
\hline & $O$ & $E$ & $S M R$ & $O$ & $\boldsymbol{E}$ & $S M R$ & $O$ & $\boldsymbol{E}$ & $S M R$ \\
\hline $\begin{array}{l}1-4 \\
5-9 \\
10-14 \\
15-19 \\
20-24 \\
\geqslant 25\end{array}$ & $\begin{array}{r}497 \\
902 \\
1329 \\
1807 \\
2012 \\
2311\end{array}$ & $\begin{array}{r}574.5 \\
931 \cdot 5 \\
1257.6 \\
1661.6 \\
1804.6 \\
2236.5\end{array}$ & $\begin{array}{r}87 \\
97 \\
106 \\
109 \\
111 \\
103\end{array}$ & $\begin{array}{l}137 \\
242 \\
371 \\
502 \\
552 \\
683\end{array}$ & $\begin{array}{l}126 \cdot 6 \\
224 \cdot 0 \\
314 \cdot 3 \\
425 \cdot 2 \\
473 \cdot 7 \\
601 \cdot 4\end{array}$ & $\begin{array}{l}108 \\
108 \\
118 \\
118 \\
117 \\
114\end{array}$ & $\begin{array}{r}360 \\
660 \\
958 \\
1305 \\
1460 \\
1628\end{array}$ & $\begin{array}{r}447.9 \\
707.5 \\
943.3 \\
1236.4 \\
1330.9 \\
1635.1\end{array}$ & $\begin{array}{r}80 \\
93 \\
102 \\
106 \\
110 \\
100\end{array}$ \\
\hline Total & 8858 & $8466 \cdot 3$ & 105 & 2487 & $2165 \cdot 2$ & 115 & 6371 & $6301 \cdot 1$ & 101 \\
\hline
\end{tabular}


Table 4 Cancer mortality for the total study population 1946-80

\begin{tabular}{|c|c|c|c|c|}
\hline Site & $I C D 8 t h$ & $O$ & $E$ & $S M R$ \\
\hline $\begin{array}{l}\text { Lip } \dagger \\
\text { Tongue } \dagger \\
\text { Mouth } \dagger \\
\text { Pharynx } \dagger \\
\text { Oesophagus } \\
\text { Stomach } \\
\text { Small intestine } \dagger \\
\text { Large intestine } \dagger \\
\text { Rectum } \\
\text { Liver } \dagger \\
\text { Gall bladder } \dagger \\
\text { Pancreas } \\
\text { Nose, sinuses } \dagger \\
\text { Larynx } \dagger \\
\text { Lung } \\
\text { Bone } \dagger \\
\text { Skin } \dagger \\
\text { Breast } \dagger \\
\text { Prostate } \\
\text { Testis } \dagger \\
\text { Other genital } \dagger \\
\text { Bladder } \\
\text { Other urinary } \dagger \\
\text { Brain } \dagger \\
\text { Thyroid } \\
\text { Lympho } \\
\text { Hodgkins } \dagger \\
\text { Myeloma } \\
\text { Leukaemia }\end{array}$ & $\begin{array}{l}140 \\
141 \\
143-5 \\
146-9 \\
150 \\
151 \\
152 \\
153 \\
154 \\
155 \\
156 \\
157 \\
160 \\
161 \\
162,3 \\
170 \\
172,3 \\
174 \\
185 \\
186 \\
187 \\
188 \\
189 \\
191,2 \\
193 \\
200,202 \\
201 \\
203 \\
204-207\end{array}$ & $\begin{array}{c}1 \\
7 \\
7 \\
20 \\
73 \\
282^{*} \\
2 \\
124 \\
104 \\
22^{*} \\
18 \\
84 \\
3 \\
27 \\
1191^{* * *} \\
11 \\
13 \\
2 \\
59\left(^{*}\right) \\
4\left(^{*}\right) \\
3 \\
78 \\
36 \\
51 \\
8 \\
38 \\
16 \\
14 \\
49\end{array}$ & \begin{tabular}{r|}
$1 \cdot 0$ \\
$7 \cdot 0$ \\
$5 \cdot 8$ \\
$14 \cdot 8$ \\
$58 \cdot 8$ \\
$245 \cdot 9$ \\
$4 \cdot 4$ \\
$130 \cdot 3$ \\
$97 \cdot 1$ \\
$12 \cdot 8$ \\
$13 \cdot 2$ \\
$90 \cdot 6$ \\
$4 \cdot 9$ \\
$20 \cdot 4$ \\
$892 \cdot 7$ \\
$9 \cdot 0$ \\
$18 \cdot 5$ \\
$2 \cdot 8$ \\
$79 \cdot 7$ \\
$10 \cdot 3$ \\
$3 \cdot 3$ \\
$74 \cdot 1$ \\
$37 \cdot 3$ \\
$59 \cdot 0$ \\
$4 \cdot 0$ \\
$40 \cdot 8$ \\
$24 \cdot 3$ \\
$19 \cdot 6$ \\
$51 \cdot 7$ \\
\end{tabular} & $\begin{array}{r}100 \\
100 \\
121 \\
135 \\
124 \\
115 \\
45 \\
95 \\
107 \\
172 \\
136 \\
93 \\
61 \\
132 \\
133 \\
122 \\
70 \\
71 \\
74 \\
39 \\
91 \\
105 \\
97 \\
86 \\
200 \\
93 \\
66 \\
71 \\
95\end{array}$ \\
\hline All neoplasms & $140-239$ & $2487 * * *$ & $2165 \cdot 2$ & 115 \\
\hline
\end{tabular}

Two tailed tests throughout.

$* \mathrm{p}<0.05 ; * * * \mathrm{p}<0.001$.

() Indicates significant deficit.

†Expectations were calculated on the basis of rates for England and Wales and rates for Scotland, except for those sites marked with a ( $\dagger$ ), for which rates for England and Wales only were used.

lung, and all neoplasms, and statistically significant deficits for cancers of the prostate and testis.

Table 5 shows observed and expected numbers of deaths by industry sector for seven causes of interest. SMRs are higher for the general rubber goods sector than for the tyre sector for all causes, all neoplasms, and cancers of the oesophagus, stomach, and lung.

The analyses shown in table 5 were repeated for each of the three entry cohorts. For the general rubber goods sector, a pattern of the highest SMR being found for the first entry cohort and the lowest SMR for the most recent entry cohort was found for all causes and for cancer of the lung. For the tyre sector, this pattern was not found for any of the seven causes of death investigated, and for cancers of the $\stackrel{\mathbb{2}}{\rightarrow}$ oesophagus, stomach, and liver the highest SMRs $\overrightarrow{0}$ were found among the most recent entry cohort.

Table 6 shows observed and expected numbers of deaths for five sites of cancer by successive periods? from first employment (irrespective of how long any요 individual remains in the industry). No clear trends $\exists$ are shown. For cancer of the lung the highest SMR is found in the first period of follow up (within ten years? from first employment).

Observed and expected numbers of deaths by first $₹$ occupation were calculated for cancers of the oesophagus, stomach, liver, lung, and bladder. Com- $>$ pared with the general population, statistically을.

Table 5 Cause specific mortality by industry sector: 1946-80

\begin{tabular}{|c|c|c|c|c|c|c|}
\hline \multirow{2}{*}{$\begin{array}{l}\text { Cause of death } \dagger \\
\text { Ca oesophagus } \\
\text { Ca stomach } \\
\text { Ca liver } \\
\text { Ca lung } \\
\text { Ca bladder } \\
\text { All neoplasms } \\
\text { All causes }\end{array}$} & \multicolumn{3}{|c|}{ Tyre sector } & \multicolumn{3}{|c|}{ General rubber goods sector } \\
\hline & $\begin{array}{c}57 \\
237^{*} \\
20^{*} \\
988^{* * *} \\
69 \\
2082^{* * *} \\
7731\end{array}$ & $\begin{array}{r}50 \cdot 1 \\
208 \cdot 4 \\
10 \cdot 9 \\
757 \cdot 6 \\
62 \cdot 7 \\
1838 \cdot 7 \\
7193 \cdot 1\end{array}$ & $\begin{array}{l}114 \\
114 \\
183 \\
130 \\
110 \\
113 \\
102\end{array}$ & $\begin{array}{c}16^{*} \\
45 \\
2 \\
203^{* * *} \\
9 \\
405^{* * *} \\
1527^{* * *}\end{array}$ & $\begin{array}{r}8.7 \\
37.6 \\
2.0 \\
135.1 \\
11.4 \\
326.7 \\
1273.2\end{array}$ & $\begin{array}{r}184 \\
120 \\
100 \\
150 \\
79 \\
124 \\
120\end{array}$ \\
\hline \multicolumn{7}{|c|}{$\begin{array}{l}\text { †See table } 4 \text { for ICD categories. } \\
{ }^{* p}<0.05 ;{ }^{* * *} p<0.001\end{array}$} \\
\hline
\end{tabular}


Table 6 Cancer mortality 1946-80: SMRs (with observed numbers) by years from first employment. (Observed numbers of deaths on which the SMRs are based in parentheses)

\begin{tabular}{lllll}
\hline Cause of death & \multicolumn{2}{l}{ Years from first employment } & Total \\
\cline { 2 - 4 } & $1-9$ & $10-19$ & $\geqslant 20$ & \\
\hline Ca oesophagus & $83(6)$ & $129(24)$ & $130(43)$ & $124(73)$ \\
Ca stomach & $105(52)$ & $146(129)$ & $93(101)$ & $115(282)$ \\
Ca liver & $95(2)$ & $195(8)$ & $179(12)$ & $172(22)$ \\
Ca lung & $150(197)$ & $126(384)$ & $123(560)$ & $133(1191)$ \\
Ca bladder & $101(10)$ & $122(30)$ & $96(38)$ & $105(78)$ \\
\hline
\end{tabular}

significant excesses were found for the following: cancer of the stomach among those compounding, weighing, and mixing (occupation 2, Obs $=32$, SMR $=152$ ); cancer of the liver among those extruding and calendering (occup 4, O = 4, SMR = 364); and cancer of the lung among those compounding, weighing, and mixing (occup $2, \mathrm{O}=103, \mathrm{SMR}=134$ ), engaged in component assembly (occup 5, O $=402$, SMR = 138), inspectors and painters (occup 7, $O=$ 46, SMR $=190$ ), workers in finished goods (occup 8 , $O=73$, SMR = 145), site and transport workers (occup 9, $O=95$, SMR $=154$ ), and maintenance workers (occup 10, $O=211, S M R=127$ ).

\section{REGRESSION MODELS AND LIFE TABLES}

The method of regression models and life tables was used to investigate the possibility of an association between the risk of mortality for given sites of cancer (and other causes) and duration of employment in the rubber industry or duration of employment in particular departments.
Table 7 shows the overall test statistics, derived from comparing the duration of employment in the rubber industry of those dying from causes of interest with those of all matching survivors. Statistically significant negative test statistics are shown for all causes, all cancers, cancers of the oesophagus and lung, and non-malignant diseases of the respiratory system. The presence of a survivor population effect ${ }^{8}$ in the data will tend to produce negative statistics for these particular tests.

A significant positive test statistic is shown for cancer of the stomach. Non-significant positive statistics are shown for cancers of the bladder and liver.

The method readily allows an inspection of the contribution from subcohorts to the overall test statistic, and table 8 shows statistics for mortality from cancer of the stomach by levels of controlling variables. The significance of the overall test statistic can be seen to be dependent on the findings for deaths occurring among the first entry cohort, among workers in the tyre factories, and occurring after ten years

Table 7 Testing the null hypothesis of no effect from duration of employment in the rubber industry on risks of mortality by the method of RMLT.† (Test factor = cumulative duration of employment in the rubber industry)

\begin{tabular}{|c|c|c|c|c|c|}
\hline Cause of death & $I C D$ 8th & No of deaths & $\begin{array}{l}\text { Mean exposure } \\
\text { of deaths } \ddagger\end{array}$ & $\begin{array}{l}\text { Mean difference } \\
\text { in exposure§ }\end{array}$ & Test statistic $\|$ \\
\hline $\begin{array}{l}\text { Ca buccal cavity } \\
\text { Ca oesophagus } \\
\text { Ca stomach } \\
\text { Ca liver } \\
\text { Ca digestive system } \\
\text { Ca larynx } \\
\text { Ca lung } \\
\text { Ca skin } \\
\text { Ca bladder } \\
\text { RES neoplasms } \\
\text { Leukaemia } \\
\text { All cancers }\end{array}$ & $\begin{array}{l}140-149 \\
150 \\
151 \\
155 \\
150-159 \\
161 \\
162-63 \\
172-73 \\
188 \\
200-209 \\
204-207 \\
140-209\end{array}$ & $\begin{aligned} 36 \\
73 \\
282 \\
22 \\
715 \\
27 \\
1191 \\
13 \\
78 \\
117 \\
49 \\
2468\end{aligned}$ & $\begin{array}{r}7 \cdot 3 \\
7 \cdot 2 \\
9 \cdot 9 \\
10 \cdot 3 \\
9 \cdot 3 \\
8 \cdot 6 \\
9 \cdot 1 \\
8 \cdot 3 \\
10 \cdot 8 \\
8 \cdot 9 \\
8 \cdot 6 \\
9 \cdot 2\end{array}$ & $\begin{array}{l}-1.6 \\
-2.8 \\
+0.9 \\
+0.7 \\
-0.1 \\
-1.1 \\
-0.4 \\
-0.6 \\
+1.0 \\
-0.5 \\
-0.7 \\
-0.3\end{array}$ & $\begin{array}{l}-1 \cdot 30 \\
-3.04^{* *} \\
+2 \cdot 19^{*} \\
+0.44 \\
-0.27 \\
-0.76 \\
-2.08^{*} \\
-0.32 \\
+1.13 \\
-0.74 \\
-0.69 \\
-2.01^{*}\end{array}$ \\
\hline \multirow{2}{*}{$\begin{array}{l}\text { Diseases circulatory } \\
\text { system } \\
\text { Diseases respiratory } \\
\text { system }\end{array}$} & $390-458$ & 3933 & $9 \cdot 4$ & $-0 \cdot 1$ & $-1 \cdot 10$ \\
\hline & $460-519$ & 1294 & 8.9 & -0.4 & $-2.09^{*}$ \\
\hline All causes & & 8858 & 8.9 & -0.4 & $-4 \cdot 81^{* * *}$ \\
\hline
\end{tabular}

*p < 0.05; **p < 0.01; ***p < 0.001 (two tailed tests).

tControlling for age at hire $(15-, 20-, 25-, 30-, 35-, 45-, \geqslant 55)$, entry cohort, English/Scottish factories, general rubber goods/tyre sector. In units of years of employment in the rubber industry.

\$Mean difference in exposure between deaths and matching survivors in units of years of employment in the rubber industry.

Assymptotically normally distributed. 
Table 8 Testing the null hypothesis of no effect from duration of employment in the rubber industry on mortality from cancer of the stomach over levels of controlling variables by the method of RMLT. $\dagger$ (Test factor = cumulative duration of employment in the rubber industry)

\begin{tabular}{|c|c|c|c|}
\hline Controlling variable & No of deaths & $\begin{array}{l}\text { Mean difference } \\
\text { in exposure }\end{array}$ & Test statistic\| \\
\hline $\begin{array}{l}\text { By entry cohort: } \\
1946-50 \\
1951-55 \\
1956-60 \\
\text { By industry sector: }\end{array}$ & $\begin{array}{r}169 \\
67 \\
46\end{array}$ & $\begin{array}{l}+1 \cdot 3 \\
+0.5 \\
+0.1\end{array}$ & $\begin{array}{l}+2 \cdot 16^{*} \\
+0.68 \\
+0.13\end{array}$ \\
\hline $\begin{array}{l}\text { Tyre } \\
\text { General rubber goods } \\
\text { By years of follow }\end{array}$ & $\begin{array}{r}237 \\
45\end{array}$ & $\begin{array}{l}+1 \cdot 0 \\
+0 \cdot 3\end{array}$ & $\begin{array}{l}+2 \cdot 26^{*} \\
+0 \cdot 27\end{array}$ \\
\hline $\begin{array}{l}\text { By years of follow up: } \\
1-9 \\
10-19 \\
\geqslant 20 \\
\text { Total }\end{array}$ & $\begin{array}{r}52 \\
129 \\
101 \\
282\end{array}$ & $\begin{array}{l}-0.2 \\
+0.6 \\
+1.8 \\
+0.9\end{array}$ & $\begin{array}{l}-0.73 \\
+1.26 \\
+1.94 \\
+2.19\end{array}$ \\
\hline
\end{tabular}

${ }^{*} \mathrm{p}<0.05$.

from first employment. These groupings are not mutually exclusive.

A similar tabulation was provided for mortality from cancer of the lung. All test statistics were negative. For cancer of the bladder, a positive statistic $(1 \cdot 32)$ was found for deaths occurring among the first entry cohort, whereas a small negative statistic $(-0.08)$ was found for deaths occurring among the two later entry cohorts combined.

"Exposure" was here estimated as overall duration of employment in the rubber industry. If a hazard were only operating in certain departments, however, such a test would "dilute" any effect. It was, therefore, important to test the null hypothesis of no effect on cancer mortality from working in specific types of jobs.

Table 9 shows test statistics comparing the $\stackrel{\circ}{\supset}$ duration of employment in jobs principally associated $\vec{c}$ with "dust" exposure of those who have died from causes of interest with those of all matching survivors. None of the statistics shown achieves significance, $\vec{\bullet}$ although the positive test statistic for cancer of the stomach approaches statistical significance. Con- $\square$ tributions from subcohorts to the overall test statistic for cancer of the stomach were obtained, and a significant statistic was found for deaths occurring among the first entry cohort $(t=+1.97, p<0.05)$. There is a negative test statistic for cancer of the lung.

Table 9 Testing the null hypothesis of no effect from duration of employment in dust exposure jobs on risks of mortality by the method of RMLT.* (Test factor = cumulative duration of employment in jobs 1, 2, or 4)

\begin{tabular}{|c|c|c|c|c|c|}
\hline Cause of death & $I C D 8 t h$ & No of deaths & $\begin{array}{l}\text { Mean exposure } \\
\text { of deathst }\end{array}$ & $\begin{array}{l}\text { Mean difference } \\
\text { in exposure } \neq\end{array}$ & Test statistic§ \\
\hline $\begin{array}{l}\text { Ca buccal cavity } \\
\text { Ca oesophagus } \\
\text { Ca stomach } \\
\text { Ca liver } \\
\text { Ca digestive system } \\
\text { Ca larynx } \\
\text { Ca lung } \\
\text { Ca skin } \\
\text { Ca bladder } \\
\text { RES neoplasms } \\
\text { Leukaemia } \\
\text { All cancers }\end{array}$ & $\begin{array}{l}140-149 \\
150 \\
151 \\
155 \\
150-159 \\
161 \\
162-63 \\
172-73 \\
188 \\
200-209 \\
204-207 \\
140-209\end{array}$ & $\begin{aligned} 36 \\
73 \\
282 \\
22 \\
715 \\
27 \\
1191 \\
13 \\
78 \\
117 \\
49 \\
2468\end{aligned}$ & $\begin{array}{l}1.4 \\
0.8 \\
2.1 \\
1.0 \\
1.7 \\
2.1 \\
1.4 \\
1.8 \\
2.1 \\
1.2 \\
0.9 \\
1.6\end{array}$ & $\begin{array}{l}-0.1 \\
-0.4 \\
+0.4 \\
-0.6 \\
+0.1 \\
+0.7 \\
-0.2 \\
+0.8 \\
+0.3 \\
-0.2 \\
-0.5 \\
-0.1\end{array}$ & $\begin{array}{l}-0.09 \\
-0.86 \\
+1.66 \\
-0.63 \\
+0.76 \\
+0.94 \\
-1.45 \\
+0.90 \\
+0.60 \\
-0.57 \\
-0.90 \\
-0.27\end{array}$ \\
\hline $\begin{array}{l}\text { Diseases circulatory } \\
\text { system } \\
\text { Diseases respiratory } \\
\text { system }\end{array}$ & $\begin{array}{l}390-458 \\
460-519\end{array}$ & $\begin{array}{l}3933 \\
1294\end{array}$ & $\begin{array}{l}1 \cdot 7 \\
1 \cdot 7\end{array}$ & $\begin{array}{l}+0 \cdot 1 \\
+0 \cdot 1\end{array}$ & $\begin{array}{l}+0.80 \\
+0.97\end{array}$ \\
\hline All causes & & 8858 & 1.6 & $+0 \cdot 1$ & +0.77 \\
\hline
\end{tabular}

*Controlling for age at hire (15-, 20-, 25-, 30-, 35-, 45-, $\geqslant 55)$, entry cohort, English/Scottish factories, general rubber goods/tyre sector, and duration of employment in the rubber industry $(1-2,3-7, \geqslant 8$ years).

tIn units of years of employment in jobs 1,2 , or 4 .

† Mean difference in exposure between deaths and matching survivors in units of years of employment in jobs 1,2 , or 4.

§Asymptotically normally distributed. 
Table 10 Testing the null hypothesis of no effect from duration of employment in fume and/or solvent exposure jobs on risks of mortality by the method of RMLT. $\dagger$ (Test factor = cumulative duration of employment in jobs $4,5,6$, or 7 )

\begin{tabular}{|c|c|c|c|c|c|}
\hline Cause of death & $I C D 8 t h$ & No of deaths & $\begin{array}{l}\text { Mean exposure } \\
\text { of deaths } \ddagger\end{array}$ & $\begin{array}{l}\text { Mean difference } \\
\text { in exposure§ }\end{array}$ & Test statistic $\|$ \\
\hline $\begin{array}{l}\text { Ca buccal cavity } \\
\text { Ca oesophagus } \\
\text { Ca stomach } \\
\text { Ca liver } \\
\text { Ca digestive system } \\
\text { Ca larynx } \\
\text { Ca lung } \\
\text { Ca skin } \\
\text { Ca bladder } \\
\text { RES neoplasms } \\
\text { Leukaemia } \\
\text { All cancers }\end{array}$ & $\begin{array}{l}140-149 \\
150 \\
151 \\
155 \\
150-159 \\
161 \\
162-63 \\
172-73 \\
188 \\
200-209 \\
204-207 \\
140-209\end{array}$ & $\begin{aligned} 36 \\
73 \\
282 \\
22 \\
715 \\
27 \\
1191 \\
13 \\
78 \\
117 \\
49 \\
2468\end{aligned}$ & $\begin{array}{l}2 \cdot 7 \\
3 \cdot 9 \\
4 \cdot 7 \\
5 \cdot 4 \\
4 \cdot 8 \\
3 \cdot 6 \\
5 \cdot 0 \\
5 \cdot 1 \\
6 \cdot 1 \\
4 \cdot 7 \\
4 \cdot 3 \\
4 \cdot 3\end{array}$ & $\begin{array}{r}-1.2 \\
+0.1 \\
-0.2 \\
-0.2 \\
0.0 \\
-0.8 \\
+0.3 \\
+0.5 \\
+0.8 \\
-0.1 \\
-0.3 \\
-0.3\end{array}$ & $\begin{array}{l}-1.44 \\
+0.16 \\
-0.67 \\
-0.12 \\
-0.09 \\
-0.82 \\
+1.65 \\
+0.35 \\
+1.03 \\
-0.16 \\
-0.42 \\
-0.38\end{array}$ \\
\hline \multirow{2}{*}{$\begin{array}{l}\text { Diseases circulatory } \\
\text { system } \\
\text { Diseases respiratory } \\
\text { system }\end{array}$} & $390-458$ & 3933 & $4 \cdot 7$ & -0.2 & $-2.01^{*}$ \\
\hline & $460-519$ & 1294 & $4 \cdot 3$ & $-0 \cdot 3$ & $-1.98^{*}$ \\
\hline All causes & & 8858 & $4 \cdot 6$ & $-0 \cdot 1$ & -1.92 \\
\hline
\end{tabular}

*p<0.05.

tControlling for age at hire $(15-, 20-, 25-, 30-, 35-, 45-, \geqslant 55)$, entry cohort, English/Scottish factories, general rubber goods/tyre sector, and duration of employment in the rubber industry $(1-2,3-7,>8$ years).

tIn units of years of employment in jobs $4,5,6$, or 7 .

\$Mean difference in exposure between deaths and matching survivors in units of years of employment in jobs 4, 5, 6, or 7 .

HAsymptotically normally distributed.

Table 10 shows test statistics comparing the duration of employment in jobs principally associated with "fume and/or solvent" exposure of those who have died from causes of interest with those of all matching survivors. The test statistic for cancer of the lung approaches statistical significance $(p<0 \cdot 10)$. Table 11 shows the contributions from subcohorts to the overall test statistic for cancer of the lung. The positive statistic for deaths occurring among the first entry cohort approaches statistical significance ( $p<$ $0 \cdot 10)$. The positive statistic for deaths occurring among workers in the tyre sector is significant at the $1 \%$ level, whereas a negative test statistic is found for deaths among workers in the general rubber goods sector.

Several analyses were also carried out in which the mortality of one group of workers was compared directly with the mortality of another group of workers, using an internal rather than an external standard. For workers in the tyre sector, the risk of dying from lung cancer was 0.88 that of workers in the general rubber goods sector. This was not statistically significantly different from unity. A similar relative risk for all causes $(0 \cdot 86)$ was statistically significant at the $1 \%$ level. These risks are numerically similar to the ratios of the appropriate SMRs.

The risk of dying from lung or bladder cancer was higher among those employed in jobs $4,5,6$, or 7 for at least 12 months compared with those never so employed, but these differences did not approach sta- tistical significance (relative risks of 1.04 and 1.32 respectively).

The risk of dying from stomach cancer was higher among those employed in jobs 1, 2, or 4 for at least 12 months compared with those never so employed (relative risk $=1.29$ ). This difference approached statistical significance.

The risk of dying from lung cancer was lower among those employed in jobs $4,5,6$, or 7 in the tyre sector for at least 12 months compared with those similarly employed in the general rubber goods sector (relative risk $=0.92$ ). This difference did not approach statistical significance.

\section{FITTING OF MODELS}

Cancer of the stomach

A simple model (appendix A) allowing for doubling dose was applied to mortality from cancer of the stomach in relation to duration of employment in the industry (irrespective of which departments were worked in). Results (maximum likelihood estimates) may be summarised as follows:

doubling dose (D): exposure (or insult) equivalent to that received in $\mathbf{4 0}$ years of employment in the industry (95\% confidence limits $17-500$ years).

The percentage of deaths from stomach cancer attributable to occupational exposure (including any synergistic effect with other factors), assuming the above model, was estimated by examining the excess 
Table 11 Testing the null hypothesis of no effect from duration of employment in fume and/or solvent exposure jobs on mortality from cancer of the lung and bronchus over levels of controlling variables by the method of RMLT. $\dagger$ (Test factor = cumulative duration of employment in jobs 4, 5, 6, or 7)

\begin{tabular}{|c|c|c|c|}
\hline Controlling variable & No of deaths & $\begin{array}{l}\text { Mean difference } \\
\text { in exposure } \$\end{array}$ & Test statistic\| \\
\hline $\begin{array}{r}\text { By cohort: } \\
1946-50 \\
1951-55 \\
1956-60\end{array}$ & $\begin{array}{l}713 \\
314 \\
164\end{array}$ & $\begin{array}{l}+0.4 \\
+0.1 \\
+0.2\end{array}$ & $\begin{array}{l}+1 \cdot 70 \\
+0.18 \\
+0.46\end{array}$ \\
\hline $\begin{array}{l}\text { By duration of employme } \\
1-2 \\
3-7 \\
\geqslant 8\end{array}$ & $\begin{array}{l}339 \\
319 \\
533\end{array}$ & $\begin{array}{l}-0.2 \\
+0 \cdot 1 \\
+0.7\end{array}$ & $\begin{array}{l}-2 \cdot 29 * \\
+0.81 \\
+1.86\end{array}$ \\
\hline $\begin{array}{l}\text { Tyre } \\
\text { General rubber goods }\end{array}$ & $\begin{array}{l}988 \\
203\end{array}$ & $\begin{array}{l}+0.5 \\
-0.7\end{array}$ & $\begin{array}{l}+2 \cdot 58^{* *} \\
-1.80\end{array}$ \\
\hline $\begin{array}{l}\text { By years of rollow up: } \\
1-9 \\
10-19 \\
\geqslant 20 \\
\text { Total }\end{array}$ & $\begin{array}{r}197 \\
384 \\
610 \\
1191\end{array}$ & $\begin{array}{l}+0.2 \\
+0.2 \\
+0.3 \\
+0.3\end{array}$ & $\begin{array}{l}+0.87 \\
+1.00 \\
+1.18 \\
+1.65\end{array}$ \\
\hline
\end{tabular}

$\dagger, \S, \|$ See footnotes $t, \S, \|$ for table 10.

$*_{p}<0.05 ;{ }^{* *} p<0.01$.

risk predicted by the model for those dying from this disease (percentage attributable $18 \%, 95 \%$ confidence limits $2 \%-32 \%$ ) (appendix B).

A more complex model allowing for cancer latency and doubling dose (appendix A) was applied to these data. Results (mle) may be summarised as follows:

(1) doubling dose (D) : exposure (or insult) equivalent to that received in 20 years of employment in the industry $(95 \%$ confidence limits 8-100 years, given that $\mathrm{L}=25$ years).

(2) optimum latent period (L):25 years.

The percentage of deaths from stomach cancer attributable to occupational exposure (including any synergistic effects with other factors), assuming the above model, was similarly estimated (percentage attributable $23 \%$, $95 \%$ confidence limits $7 \%-40 \%$ ). The inclusion of this further variable (cancer latency) could not be justified on the grounds of statistical significance (simple model: maximum log likelihood 2.30; complex model: maximum log likelihood 3.44). (For each additional variable included in the model, an increase in log likelihood of 1.96 indicates statistical significance.)

The above models assumed a linear dose effect (exponent for non-linearity, $\mathrm{E}=1 \cdot 0$ ). It was not possible to discriminate between values of 0.5 and 1.0 for this parameter. A value of $\mathbf{2 . 0}$ for this exponent tended to produce lower log likelihoods and could be excluded.

Similar models were applied for exposure estimated as duration of employment in dust jobs (jobs 1,2 , or 4). Maximum likelihood estimates were not statistically significantly different from zero.
Cancer of the lung

A simple model allowing for doubling dose was $\overrightarrow{0}$ applied to mortality from cancer of the lung in relation to employment in jobs principally associated $\square$ with fume and/or solvent exposure (jobs $4,5,6$, or 7 ). 오 This analysis was first carried out for the tyre sector. Results (mle) may be summarised as follows: doubling dose (D): exposure (or insult) equiv- $\frac{0}{\mathbb{Q}}$ alent to that received in 65 years of employment $\stackrel{\circ}{\rightarrow}$ in jobs principally associated with fume and/or solvent exposure (95\% confidence limits $32-400$ years).

The percentage of deaths from lung cancer occurring among workers in the tyre sector and attributable to occupational exposure (including any syn- 3 ergistic effects with other factors), assuming the above $\frac{5}{3}$ model, was also estimated. (Percentage attributable $6 \%, 95 \%$ confidence limits $1 \%-11 \%$.)

The above analysis did not include a variable allowing for cancer latency. When such a variable was included in the analysis, maximum likelihood esti- $\rightarrow$ mates were as follows:

(1) doubling dose $\mathrm{D}$ : exposure (or insult) equiv- $N$ alent to that received in 30 years of employment ${ }^{\circ}$ in jobs principally associated with fume and/or 0 solvent exposure (95\% confidence limits 15-125 స్ట years, given that $\mathrm{L}=5$ years).

(2) optimum latent period (L): 5 years.

The percentage of deaths from lung cancer occur $-\frac{\bar{\Phi}}{\Phi}$ ring among workers in the tyre sector and attri- $\stackrel{\oplus}{+}$ butable to occupational exposure (including any syn- 7 ergistic effects with other factors), assuming the above $\stackrel{\circ}{\circ}$ model, was also estimated. (Percentage attributable $\stackrel{\square}{\square}$ 
$6 \%, 95 \%$ confidence limits $2 \%-11 \%$.)

The inclusion of this further variable (cancer latency) could not be justified on the grounds of statistical significance, as the log likelihood (3.79) was only a little larger than that for the simpler model (3.16).

The above models assume a linear dose effect (exponent for non-linearity, $\mathrm{E}=1 \cdot 0$ ). Other possible values of $E$ could not be confidently excluded.

When the above analyses were repeated for the total study population (tyre and general rubber goods sector), maximum likelihood estimates were not statistically significantly different from zero.

\section{Discussion}

In the general population there is a steep positive social class gradient for mortality from all cancers and cancers of the stomach, oesophagus, and respiratory system and for many other sites of cancer. ${ }^{9}$ There is a negative social class gradient for certain other sites of cancer, melanoma and cancer of the testis, for example. It is, therefore, not surprising that compared with the general population this study cohort had an overall significant excess mortality from cancer of the stomach and cancer of the lung, nor it is surprising that compared with the general population there was a deficit of deaths from cancer of the testis. (There was also, in fact, low overall mortality from melanoma.)

The key question to be answered was this: given that the mortality experience of the cohort differed from that of the general population in several ways, were occupational factors concerned in the observed pattern of mortality? To address this question we used a method involving an internal standard (RMLT). The reasonableness of any approach using an internal standard depends on the main assumption that we are comparing like with like-namely, that after controlling for certain variables, such as year of hire, age at hire, exposed and non-exposed workers in a given year of follow up in a given subgroup are similar with respect to factors other than exposure. In this study cohort all were manual workers in one industry, and nearly all would have lived in the vicinity of their place of work.

The power of any mortality study must depend not only on the number of cause specific deaths available for analysis and on the method of analysis adopted, but also on the extent of discrimination in exposure within subcohorts. In this analysis, the "exposure" variables used were relatively crude but they merit consideration.

For the first exposure estimate (duration of employment in the rubber industry), it was not possible to control for any survivor population effect in the data. This limitation would tend to produce negative test statistics. Such a statistic was indeed found for all causes of death, and could well imply that those less fit had left the industry earlier. This tendency increases the importance of the positive statistics found for cancers of the stomach, bladder, and liver.

For the remaining exposure estimates, it was possible to control for any survivor population effect in the data by stratifying over duration of employment in the industry. Nevertheless, one limitation of, say, the "dust exposure" estimates would be that some of the "non-exposed" jobs would also entail at least some exposure to dust. This would also, to some extent, work against the demonstration of any potential hazard. Also, if a carcinogen had only been present in certain departments for a few calendar years these exposure estimates would be unreliable.

Despite the above limitations, however, there was good evidence of involvement of occupational exposure in mortality from cancer of the stomach. Exposure to "fume" was not specifically implicated, whereas exposure to dust was, although the carcinogen or carcinogens involved may not be job-specific, as an overall significant finding was obtained only with exposure estimated as duration of employment in the rubber industry (irrespective of which departments were worked in).

Although the overall SMR for cancer of the oesophagus was 124 (table 5), no evidence has been found in the RMLT analysis to associate the observed excess mortality with occupational exposure. Our findings are not in agreement with those of Norell et al, who recently reported a tenfold increased risk for oesophageal cancer among vulcanisation workers. ${ }^{10}$ We understand, however, that this latter group, although described as vulcanisation workers, were not employed in the rubber industry but were, in fact, employed repairing tyres in garages.

There was an association between duration of employment in jobs principally associated with fume and/or solvent exposure and mortality from cancer of the lung among workers in the tyre sector, but no such association among workers in the general rubber goods sector. Possible explanations for these discordant results include:

(1) chance alone;

(2) a risk factor is present in the industry as a whole although job histories (defined in terms of 10 different jobs) for workers in the general rubber goods sector give no meaningful guide to levels of individual exposures to fume or solvents or both; and

(3) a risk factor associated with fume and/or solvent exposure is present in the tyre sector but not in the general rubber goods sector.

We believe the second explanation to be more likely than the third. 
Although the above association was found only in the tyre sector, it does not follow that workers in the tyre sector have a higher risk of lung cancer mortality than workers in the general rubber goods sector. The results presented in table 5 show, in fact, that this is not the case.

In the evaluation of the data relating to lung cancer it would clearly have been desirable to consider the possible influence of smoking. Unfortunately, information on smoking habit was not available. There is no good reason to believe, however, that smoking habit would correlate with duration of employment.

There was suggestive evidence of an occupational risk factor being present for cancer of the bladder among the first entry cohort, but no such evidence was found among the two later cohorts. This indicates that the withdrawal of recognised bladder carcinogens from production use in 1949 was successful in eliminating an occupational bladder cancer hazard.

A high SMR for the total study cohort was obtained for primary cancer of the liver (SMR $=172$, based on 22 deaths), although the RMLT analyses produced no statistically significant findings for occupational exposures and mortality from this site of cancer. A recent cohort study of Swedish rubber workers also found an overall excess mortality from primary cancer of the liver among production workers $(\mathrm{O}=8, \mathrm{E}=2 \cdot 0){ }^{11}$

It is not being suggested that any occupational hazards would operate precisely in the way predicted by the models that were fitted to the data. These models, however, provide our current best estimate of the size of risk factors that may have been present, as distinct from the earlier test statistics which merely indicate levels of statistical significance.

There are problems in fitting models to occupational cohort studies, particularly when occupational hygiene data are not available, resulting in wide confidence intervals around each estimated parameter. But the best estimate for the percentage of deaths from stomach cancer attributable to occupational exposures was $18 \%$. This may be an overestimate as the corresponding SMR was only 115.

Similarly, the best estimate for the percentage of deaths from lung cancer occurring among workers in the tyre sector attributable to occupational exposures was $6 \%$. This figure may, however, be an overestimate for the industry as a whole, as the RMLT analysis deliberately excluded that part of the study cohort in which it was known there was no effect-that is, the general rubber goods sector.

One interesting hypothesis relating to lung cancer that arises both from the model fitting exercise and from the observed trend in SMRs for lung cancer by period from first employment (table 6) is that for this study cohort there may have been a risk factor present in the rubber industry acting on a late stage of $\frac{\mathbb{D}}{\mathbb{2}}$ the disease process, resulting in a relatively short? interval between exposure and onset of the disease.

This study has provided further evidence of a causal association between the risks of lung and stomach cancer and occupational exposures.

\section{Appendix A}

\section{FITTING MODELS}

\section{Simple model}

Let $\mathrm{x}_{\mathrm{j}}=$ duration of employment in particular kinds $\vec{\omega}$ of jobs-for instance, dust jobs in follow up year $\mathrm{j}$. This is an estimate of dose (or exposure or insult).

Let the relative risk in follow up year $i$ be given by

$$
\mathbf{R}_{\mathbf{i}}=1+\left(\sum_{j=1}^{i} \frac{\mathbf{x}_{i}}{\mathrm{D}}\right)^{\mathbf{E}}
$$

where $D$ is the assumed doubling dose-that is, when

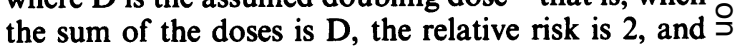
where $E$ is the exponent for non-linearity $(E=1.0$ gives a linear dose response relation).

The model assumes that risk increases with $\overparen{\varnothing}$ increasing dose and does not allow for cancer latency. $\vec{\bullet}$ The null hypothesis is that $\frac{1}{\mathrm{D}}=0$.

\section{More complex model}

Let exposure received $\mathbf{k}$ years ago have to be multiplied by a factor $W_{k}$ to give the effective dose, where $\stackrel{\circ}{\mathcal{D}}$ $\mathrm{W}_{\mathrm{k}}=\mathrm{k} / \mathrm{L} \exp (1-\mathrm{k} / \mathrm{L})$ and $\mathrm{L}$ is the optimum latent period in years.

For example, the figure shows $W_{k}$ for $L=20$ years. $W_{k}$ is less than 1.0 for all $k$ except $k=L$, thus dose has maximum effect if received 20 years ago. This $₫$ curve (equation) is being used because with one con- 3 stant $(\mathrm{L})$ the main features of any distribution of $\frac{}{3}$ latent periods are probably being described - namely, no effect at $\mathrm{t}=0$ and $\mathrm{t}=\infty$, and a maximum effect at윽 some intermediate time $t=L$.

Let cumulative effective dose by follow up year음 $\mathrm{i}$ be $Z_{\mathrm{i}}$

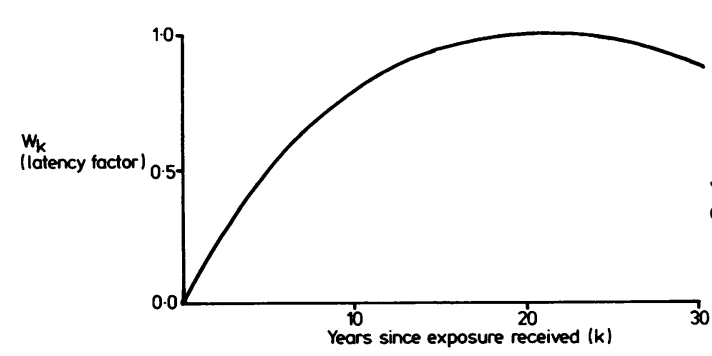

Latency factor. 
where $Z_{i}=\sum_{j=1}^{i} W_{(i-j)}, x_{j}$

Let the relative risk in follow up year $i$ be given by $\mathbf{R}_{i}$, where $R_{i}=1+\left(\frac{Z_{i}}{D}\right)^{E}$

where $\mathrm{D}$ is the assumed doubling dose for exposure received $\mathrm{L}$ years ago, and $\mathrm{E}$ is the exponent for nonlinearity.

\section{Appendix B}

\section{ESTIMATING ATTRIBUTABLE RISK}

Having obtained maximum likelihood estimates for the parameters of a model, calculate the riskspredicted by the model - for those who die from the cause of death under investigation.

Let $\mathrm{n}$ be the number of deaths, and the predicted relative risk be given by $R_{j}$ where $j=1,2$..n.

The percentage attributable risk is estimated as

$$
\frac{\sum_{j=1}^{n}\left(R_{j}-1 \cdot 0\right) / R_{j}}{n} \times 100 \text {. }
$$

References

${ }^{1}$ Parkes HG, Veys CA, Waterhouse JAH, Peters A. Cancer mortality in the British rubber industry. $\mathrm{Br} J$ Ind Med 1982; 39:209-20.

${ }^{2}$ International Agency for Research on Cancer. Monograph on the evaluation of the carcinogenic risk of chemicals to humans. Vol 28. The rubber industry. Lyon: IARC, 1982.

${ }^{3}$ Baxter PJ, Werner JB. Mortality in the British rubber industries 1967-76. London: HMSO, 1980.

${ }^{4}$ Liddell FDK, McDonald JC, Thomas DC. Methods of cohort analysis with appraisal by application to asbestos mining. Journal of the Royal Statistical Society 1977;A140:469-91.

${ }^{5}$ Cox DR. Regression models and life-tables. Journal of the Royal Statistical Society 1972;B34:187-219.

${ }^{6} \mathrm{Kneale}$ GW, Mancuso TF, Stewart AM. Hanford radiation study III: a cohort study of the cancer risks from radiation to workers at Hanford (1944-77 deaths) by the method of regression models in life-tables. Br J Ind Med 1981;38:156-66.

${ }^{7}$ Sorahan T, Waterhouse JAH. Mortality study of nickel-cadmium battery workers by the method of regression models in lifetables. Br J Ind Med 1983;40:293-300.

${ }^{8}$ Fox AJ, Collier PF. Low mortality rates in industrial cohort studies due to selection for work and survival in the industry. $\mathrm{Br} J \mathrm{Prev}$ Soc Med 1976;30:225-30.

${ }^{9}$ Office of Population Censuses and Surveys. Occupational mortality. decennial supplement for England and Wales, 1970-2. London: HMSO. (Series DS No 1.)

${ }^{10}$ Norell S, Ahlbon A, Lipping H, Osterblom L. Oesophageal cancer and vulcanisation work. Lancet 1983;i:462-3.

${ }^{11}$ Holmberg B, Westerholm P, Maasing R, et al. Retrospective cohort study of two plants in the Swedish rubber industry. Scand $J$ Work Environ Health 1983;9 supp 2:59-68. 